\title{
Therapeutic targets and microenvironment in sequential biopsies of classical Hodgkin lymphoma at diagnosis and relapse
}

\author{
Antje Schnitter ${ }^{1} \cdot$ Christian W. Kohler $^{2} \cdot$ Katharina Reddemann $^{1} \cdot$ Sarah Reinke $^{1} \cdot$ Christoph Thorns $^{3} \cdot$ Falko Fend $^{4}$. \\ Birgit Federmann ${ }^{4} \cdot$ Peter Möller $^{5} \cdot$ Monika Szczepanowski $^{1} \cdot$ Rainer Spang $^{2} \cdot$ Wolfram Klapper $^{1}$
}

Received: 20 December 2018 / Accepted: 10 February 2019 / Published online: 11 March 2019

(C) The Author(s) 2019

\begin{abstract}
Classical Hodgkin lymphoma is dominated by the non-neoplastic microenvironment, while the neoplastic Hodgkin-ReedSternberg cells compose only a minority of cells in the lymphoma tissue. Both the Hodgkin-Reed-Sternberg cells due to their expression of CD30 and PD-L1 and the microenvironment with abundant T cells and expression of PD1 are specifically targeted by new treatment concepts. We aimed to understand the dynamics of therapeutic targets in patients treated with conventional chemotherapy. We analyzed sequential biopsy specimens obtained at diagnosis and at relapse from the same patient for morphology, immunophenotype, and microenvironmental components. The morphological subtype changed between primary and relapse biopsy in $20 \%$ of cases. The immunophenotype was stable with respect to CD30, CD3, and LMP1 but variable with respect to CD15 and CD20 expression. Gene expression revealed 8 upregulated and 20 downregulated genes at relapse $(p \leq 0.05)$ with a consistent logarithmic fold change direction in at least 75\% of all cases. For PD1, we found discrepant results between gene expression analysis (decrease at relapse) and number of PD1-positive cells assessed by immunohistochemistry (unchanged at relapse). PD-L1 in the neoplastic cells appeared unchanged between primary diagnosis and relapse. The expression of the therapeutic targets CD30, PD1, and PD-L1 can reliably be assessed in tumor specimen at first diagnosis and is unchanged under conventional chemotherapy.
\end{abstract}

Keywords Hodgkin lymphoma $\cdot$ Microenvironment $\cdot$ PDL1 $\cdot$ PD1 $\cdot$ CD30

Electronic supplementary material The online version of this article (https://doi.org/10.1007/s12308-019-00350-2) contains supplementary material, which is available to authorized users.

Wolfram Klapper

wklapper@path.uni-kiel.de

1 Department of Pathology, Hematopathology Section and Lymph Node Registry, Christian-Albrecht University, Kiel, University Hospital Schleswig-Holstein (UKSH), Campus Kiel, Arnold-Heller-Strasse 3, Haus 14, 24105 Kiel, Germany

2 Statistical Bioinformatics Department, Institute of Functional Genomics, University of Regensburg, Regensburg, Germany

3 Department of Pathology, University of Lübeck, University Hospital Schleswig-Holstein (UKSH), Campus Lübeck, Lübeck, Germany

4 Department of Pathology, University of Tübingen, Tübingen, Germany

5 Department of Pathology, University of Ulm, Ulm, Germany

\section{Introduction}

Classical Hodgkin lymphoma (cHL) is characterized by an abundant microenvironment and a low number of neoplastic Hodgkin-Reed-Sternberg cells (HRSC). The composition of the microenvironment rather than the morphology or immunophenotype of the neoplastic HRSC is used to identify morphological variants of the disease, of which mixed cellularity (MC), nodular sclerosis (NS), and lymphocyte-rich are the most frequent [1]. The relative abundance of these subtypes strongly correlates with patient age at diagnosis and the socioeconomic status of the geographic area in which the patient resides [2]. The composition of the microenvironment in cHL is most likely a result of the interplay between the HRSC, which secrete multiple chemokines, and the microenvironmental cells, which provide survival signals to HRSC [3].

Although the histologically defined subtypes of cHL are not prognostically relevant under current treatment regimens [1], the microenvironment of cHL has gained considerable attention in molecular studies over the last years [4-7]. On 
the one hand, gene expression profiling of the whole lymphoma tissue indicated a correlation between the cellular composition of the microenvironment and patient outcome and suggested that a high load of macrophages within the tissue is associated with a poor prognosis $[4,8]$. On the other hand, blocking $\mathrm{T}$ cell signaling between programmed cell death 1 (PD1) expressed on T cells and PD1-ligand (PD-L1) led to exceptional therapeutic success [9].

Despite the fact that the phenotype and the histological subtypes of cHL have been known for decades, to the best of our knowledge, studies systematically analyzing the dynamics of these features are lacking. The content of macrophages in primary biopsies has been associated with outcome and is discussed as a relevant prognostic biomarker [10] but only few studies have been assessing the macrophage content in paired biopsies at diagnosis and at relapse [11]. Moreover, it is currently not known whether therapeutic targets like PD-L1/ PD1 and CD30 change under conventional chemotherapy and which biopsies need to be assessed if the status should be assessed for targeted treatment at relapse. In fact, we recently showed that the number of PD1-positive cells increased in patients relapsing after/under anti-PD1 treatment [12]. We thus analyzed multiple biopsy specimens from cHL patients and compared histological subtype, immunophenotype, and microenvironment at diagnosis and at relapse to understand which tissue needs to be analyzed when assessing the presence of therapeutic targets CD30, PD1, and PD-L1 or prognostic biomarker such as the macrophage content in cHL.

\section{Material and methods}

\section{Patients and tissue specimens}

A test cohort of patients $(n=18)$ was identified in the files of the Lymph Node Registry Kiel on the basis of the availability of formalin-fixed paraffin-embedded (FFPE) tissue specimens of sufficient size and quality obtained at the time of diagnosis and relapse. Three patients were represented by more than two biopsies (total number of sequential biopsies $n=39$ ). The morphology and immunophenotype including expression of CD30 of the test cohort were studied based on the available tissue sections. Additionally, gene expression and staining for CD68, CD163, PD1, and PD-L1 were performed using freshly cut FFPE sections. An independent validation cohort of sequential specimens was obtained from the files of the Departments of Pathology in Lübeck, Tübingen, and Ulm using the same procedure for patient identification as for the test cohort ( $n=14$ patients). The validation cohort was analyzed for morphology and immunophenotype (including CD30) using the available sections and for CD68 using freshly cut sections. The study was conducted in accordance with the recommendations of the ethics board of the Medical Faculty, University of Kiel.

The median time between primary and relapse biopsy was 38 months (range 12 to 98 ) for the test cohort and 30 months (range 12 to 105) for the validation cohort. Due to the retrospective nature of the study, clinical data on the patients were not available.

\section{Histopathology and immunophenotype}

The histological subtype and the immunophenotype were assessed by at least one experienced hematopathologist (FF, CT, PM, WK). Stainings for CD20, CD30, CD15, CD3, PAX5, and LMP1 were performed using standard techniques in the participating labs and scored as positive if any fraction of HRSC stained positive. The following antibodies and staining protocols were used: CD68 (Dako M0876, clone PG-M1, pH 6, Histofine, manual staining), CD163 (Leica NCLCD163, clone 10D6, pH 6, Histofine, manual staining), PD1 (Cell Marque 315M-96, clone MRQ22, ER1-pH 6, LeicaBond stainer), PDL1 (Cell Signaling 13,684, clone E1L3N, ER2-pH 8 Leica-Bond stainer). The number of PD1, PD-L1, CD68, and CD163-positive cells was counted in three highpower fields (HPF, 1000-fold magnification using oil immersion). The average of the three HPF was calculated for further analysis. The HPFs were selected from areas containing HRSC. At least one unambiguously identified HRSC was placed in the center of the HPF in order to determine the cell count in very close proximity to the neoplastic cells. PD-L1 expression on malignant cells was analyzed by visual inspection and scored in steps of $0 \%, 1-25 \%, 26-50 \%, 51-75 \%$, and $>76 \%$ positive HRSC.

\section{Gene expression profiling}

RNA was extracted from FFPE tissue sections using ExpressArt FFPE Clear RNA Ready Kit (AmpTec, Hamburg, Germany), as previously described [13]. Gene expression analysis was performed on a cohort of $n=39$ specimens using the Nanostring (nCounter) technology and the Immunology Code Set Kit that target 594 genes associated with the immune system (nCounter, nanoString, Seattle, USA), including 15 housekeeper genes.

Sample quality control was assessed by using the quality metrics as implemented in the Bioconductor package NanoStringQCPro in version 1.8.0 [14]. Of the 39 specimens (18 primary tumors and 21 relapse samples), 8 specimens were excluded due to low/insufficient RNA abundance. As a consequence, only 13 lymphomas remained with good quality data for both the primary and the relapse sample. For one of the 13 lymphomas, we had two sequential relapse samples for the same primary sample. We included both such that we analyzed 14 pairs in total. 
The gene expression data were normalized by first taking the $\log 2$ on the raw data and then subtracting the individual median gene count from each sample. Next, the median of all sample medians was added to each specimen to ensure positive normalized count values for each gene.

Differential gene expression analysis was performed using generalized linear models of the negative binomial family as implemented in the Bioconductor package NanoStringDiff (version 1.6.0) [15-17]. Additionally, the paired nature of the cohort was included in the model and housekeeper genes ( $n=15$ ) were excluded from analysis. Resulting $p$ values were adjusted for multiple testing according to Benjamini and Hochberg and a significance level for differential expression was set to a False Discovery Rate (FDR) of 0.05 .

\section{Results}

\section{Histological subtype, immunophenotype, and expression of CD30}

In a combined analysis of the test and validation cohorts, the histological subtype remained stable between primary and relapse biopsy in the vast majority of cases $(80 \%$, Table 1$)$. However, a change from mixed cellularity (MC) to nodular sclerosis (NS) subtype and vice versa as well as complex pattern subtype alterations over time was also observed (Table 1). A considerable number of cases varied in HRSC phenotype in sequential biopsy specimens with respect to the expression of CD15 (53\%), CD20 (36\%), and CD3 (6\%) (Table 2, Fig. 1). Expression of CD30 and the EBV protein LMP1 were unchanged between primary and relapse biopsy in all cases analyzed (Table 2). CD30 expression was detectable on virtually all HRSC at first diagnosis as well as at relapse. We did not identify a case in which the CD30 expression was absent on a considerable number of HRSC (Fig. 1).

\section{Macrophage content (CD68 and CD163)}

We analyzed macrophage marker expression in the specimens using stainings for CD163. The frequency of CD163-positive

Table 1 Change of morphological subtype in sequential biopsies in all sequential specimens analyzed $(\mathrm{MC}=$ mixed cellularity, $\mathrm{NS}=$ nodular sclerosis, complex $=$ multiple alterations in three available biopsy specimens: NS to lymphocyte depleted to NS, NS to MC to NS, and $\mathrm{MC}$ to lymphocyte rich to NS)

\begin{tabular}{ll} 
MC unchanged & $10 / 30(33 \%)$ \\
NS unchanged & $14 / 30(47 \%)$ \\
NS to MC & $1 / 30(3 \%)$ \\
MC to NS & $2 / 30(7 \%)$ \\
Complex & $3 / 30(10 \%)$ \\
\hline
\end{tabular}

macrophages did not show a significant difference between primary and relapse biopsies ( $p=0.3068$, paired $t$ test). We additionally used CD68 as macrophage marker and extended the analysis to the validation cohort but failed to find a difference between primary and relapse biopsy (Fig. 2). Gene expression analysis using Nanostring technology in the test cohort revealed 8 upregulated and 20 downregulated genes at relapse ( $p \leq 0.05$, Supplementary figure 1 , Supplementary table 1) with a consistent $\operatorname{logFC}$ direction in at least $75 \%$ of all cases. MRNA expression CD163 not significantly changed between primary biopsy and relapse confirming the findings of immunohistochemistry analysis (Supplementary tables 2 and 3). However, we were able to detect the previously reported inverse correlation of relative changes in macrophage and B cell signatures between primary and relapse specimens (Supplementary figure 2).

\section{PD1 and PD-L1}

PD1-positive cells in the microenvironment were detected only in two specimens at a low level (16\% in one primary biopsy and $2 \%$ in one relapse biopsy). None of the other specimens showed PD1-positive T cells in the 16 paired biopsies available for staining. HRSC were negative for PD1 in all cases. For 13 paired biopsies, PD-L1 staining yielded results in both the primary and the relapse biopsy (Fig. 1). PD-L1 expression in the microenvironment did not show any significant difference between primary biopsy and relapse $(p=0.9946$, paired $t$ test). More than $75 \%$ of HRSC were positive for PD-L1 in primary and relapse biopsy in 10 patients and between 50 and $75 \%$ positive HRSC in two patients. A slight change in PD-L1 expression was observed only in one patient in whom the primary biopsy showed 50-75\% and the relapse $>75 \%$ PDL1-positive HRSC.

By Nanostring gene analysis PD-L1 (CD274), mRNA expression was not different between primary and relapse confirming the results of immunohistochemistry. Of note, expression of PD1 (PDCD1) mRNA was significantly downregulated at relapse (Supplementary table 1).

\section{Discussion}

In cHL, the lymphomatous enlarged tissue is predominantly composed of a non-neoplastic microenvironment. The abundance of non-neoplastic cells allowed the development of prognostic signatures based on the composition of the microenvironment and the identification of therapeutic targets to [4-7, 18]. Especially the latter has attracted considerable attention during the last years [19]. The introduction of immune-checkpoint inhibitors that potentially interfere with the interaction of HRSC and microenvironmental cells has proven to be highly effective in cHL [9]. Since conventional 
Table 2 Immunophenotypic alterations of Hodgkin-ReedSternberg cells in primary and relapse biopsy

\begin{tabular}{llllll}
\hline & CD20 & CD3 & CD30 & CD15 & LMP1 \\
\hline Positive unchanged & $0 / 17(0 \%)$ & $0 / 17(0 \%)$ & $17 / 17(100 \%)$ & $7 / 17(41 \%)$ & $9 / 17(47 \%)$ \\
Positive to negative & $4 / 17(24 \%)$ & $1 / 17(6 \%)$ & $0 / 17(0 \%)$ & $3 / 17(18 \%)$ & $0 / 17(0 \%)$ \\
Negative to positive & $2 / 17(12 \%)$ & $0 / 17(0 \%)$ & $0 / 17(0 \%)$ & $6 / 17(35 \%)$ & $0 / 17(0 \%)$ \\
Negative unchanged & $11 / 17(65 \%)$ & $17 / 18(94 \%)$ & $0 / 17(0 \%)$ & $1 / 17(6 \%)$ & $8 / 17(53 \%)$ \\
\hline
\end{tabular}

chemotherapy cures the vast majority of cHL patients at initial disease presentation, the application of new drugs such as anti-
CD30 antibody-drug conjugates or immune-checkpoint inhibitors targeting the PD1-PD-L1 axis has been tested

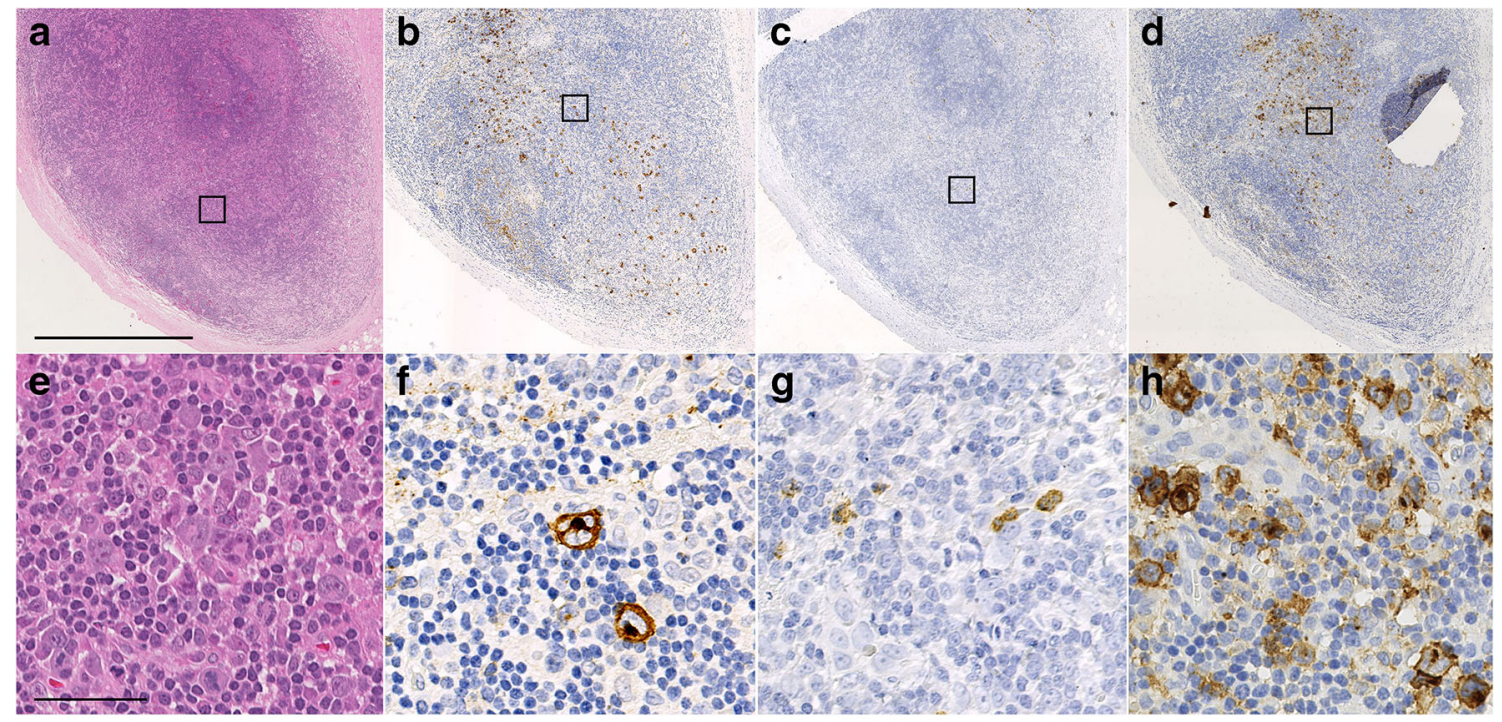

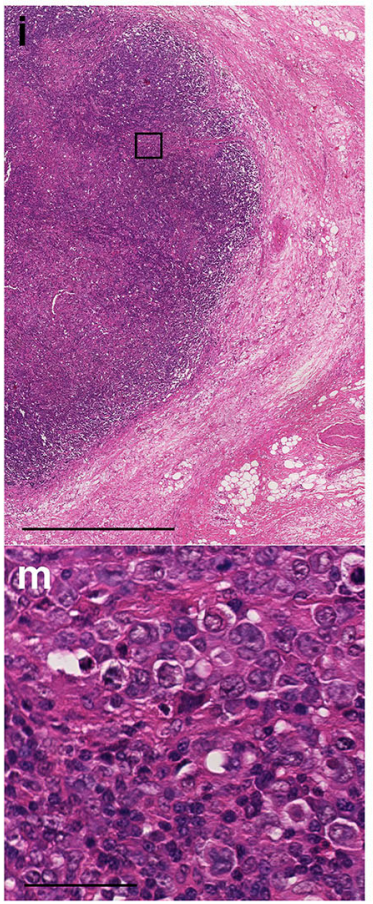

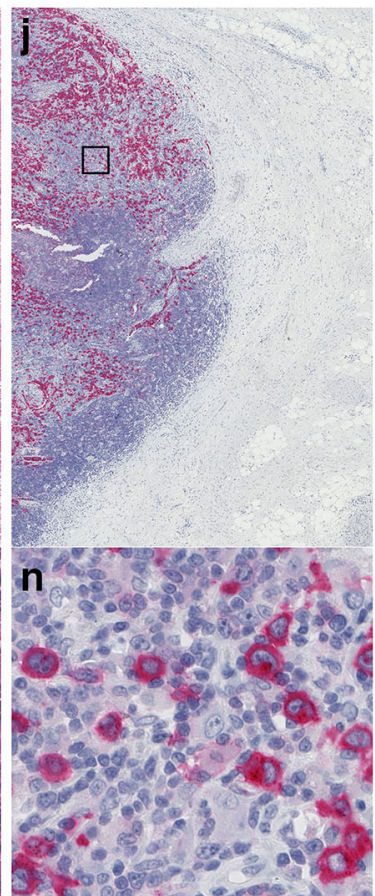

Fig. 1 Histology and immunophenotype. The upper panel represent primary (a-d low, $\mathbf{e}-\mathbf{h}$ high magnification) and the lower panel relapse biopsies (i-l low and $\mathbf{m}-\mathbf{p}$ high magnification). $\mathbf{a}, \mathbf{e}, \mathbf{i}, \mathbf{m}=$ hematoxylin and eosin staining; $\mathbf{b}, \mathbf{f}, \mathbf{j}, \mathbf{n}=\mathrm{CD} 30$ (expression unchanged); $\mathbf{c}, \mathbf{g}, \mathbf{k}, \mathbf{o}=$ CD15 (negative in primary and positive in relapse biopsy); $\mathbf{d}, \mathbf{h}, \mathbf{l}, \mathbf{p}=$

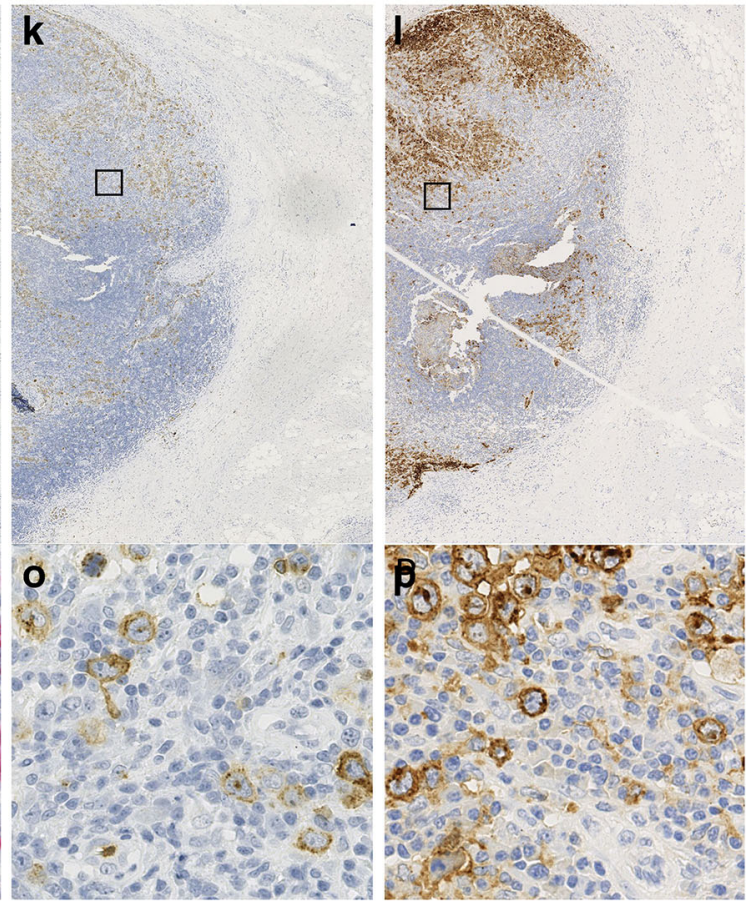

PDL1 (expression unchanged). Black boxes in low magnification indicate areas selected for high magnification of respective staining. The scale bar for low magnification represents $1000 \mu \mathrm{m}$, scale bar for high magnifications $50 \mu \mathrm{m}$ 
Fig. 2 Content of CD68-positive cells assessed immunohistochemically in sequential biopsy specimens. CD68 cell content in the test cohort $(\mathbf{a}$, $p=0.2403)$ and validation cohort (b, $p=0.7839$ ). Primary and relapse biopsy are connected by a line. $Y$-axis indicates average number of cells per three highpower fields
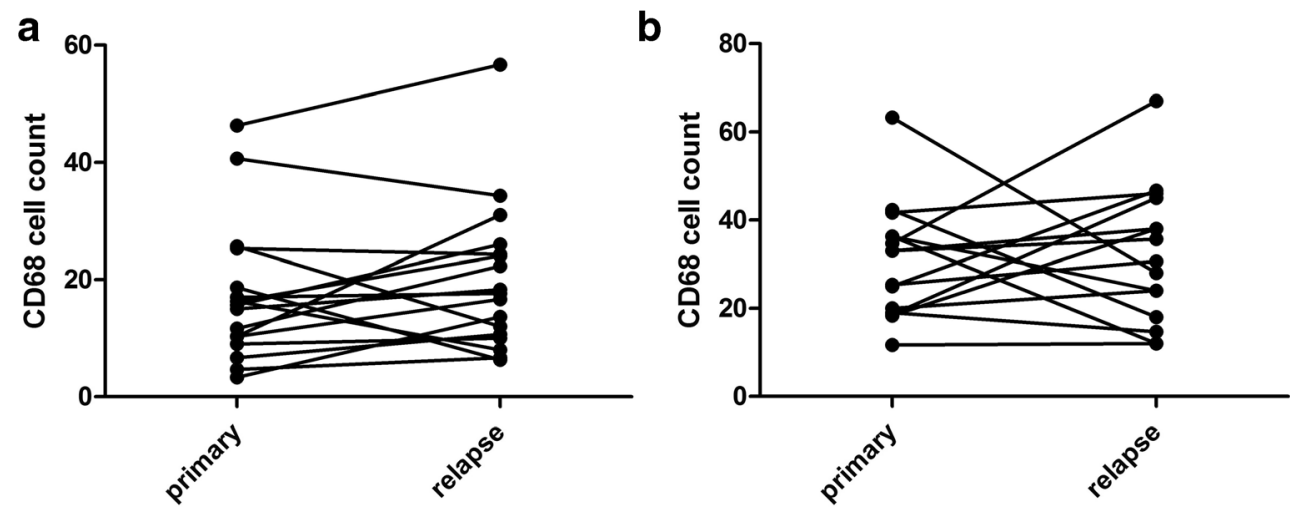

predominantly in relapsed patients [20]. Although there have been major advances in the therapy of relapsed cHL, biological studies of lymphoma tissue at relapse are very rare. Moreover, analyses of sequential biopsies of lymphomas at diagnosis and at relapse are virtually absent from the published literature until recently [11]. Therefore, we do not know so far whether predictive and prognostic biomarkers of cHL are stable between pretreatment tissue and relapse and whether the assessment of the biomarkers at initial diagnosis is valid for later relapses.

Similar to a previous report [11], we illustrate phenotypic shifts in cHL after chemotherapy exemplified in changes of the morphological subtype and the immunophenotype of HRSC. With respect to biomarkers, we found potentially relevant markers such as CD68/macrophage count to be unchanged between primary biopsy and relapse. Previously published studies suggested that CD30 expression might change in sequential biopsies [21-23]. In contrast to these previous publications, we demonstrate constant expression of CD30 between primary biopsy and relapse. Phenotype shifts between primary and relapse biopsies have been described in sequential mediastinal gray zone lymphoma [24]. However, our cohort only contains pure cHL. Of note, all biopsy specimen analyzed in our study were from the pre-brentuximab era. We cannot rule out that the variability of CD15 expression is to some extent due to technical reasons since expression can be weak or affect a subpopulation of cells only and might thus be missed by visual inspection.

PD1 and PD-L1 are both therapeutic targets and biomarker of outcome [25]. A recent publication found increasing levels of PD1-positive $\mathrm{T}$ cells in $\mathrm{cHL}$ at relapse after conventional chemotherapy [26]. We were not able to confirm these results. Both methods applied-immunohistochemistry and gene expression - did not detect an upregulation of PD1 at relapse. In fact, PD1 was downregulated on the RNA level at relapse and we did not find changes of PD1-positive cell counts at relapse. These data are in line with those obtained by another group that published PD1 levels in pairs of biopsies from primary diagnosis and relapse after conventional [27]. Unfortunately, the data of the so far only previously published gene expression data on biopsy pairs of $\mathrm{cHL}$ are not publically available to the best of our knowledge and thus cannot be used to confirm our results [11].

The discrepancy between gene expression and cell counts in our study may be explained in several ways. First, protein expression might be influenced by post-transcriptional mechanisms. Second, within a cell population, the expression of the identifying gene/protein might be variably high expressed but a broad spectrum of expression allows cells to be registered as positive by immunohistochemistry. PD1 has been shown to be downregulated in exhausted $\mathrm{T}$ cell which are primed to be reactivated [28]. We cannot exclude that this population is missed by our staining but detected by others [29]. Third, the methods of assessing cell counts used in our study are quantitative (counting) but restricted to a small preselected area in the immediate proximity of the HRSC (microenvironment) and do not necessarily reflect the cell content in the whole tissue (macroenvironment) as gene expression profiling does.

To gain further insight into the functional relevance of microenvironment changes at relapse, methods need to be applied that assess quantitatively cell counts and simultaneously allow to study the macro- and microenvironment within the tissue sections, e.g., by image analysis of whole scanned sections. Finally, spatial organization of cell types in combination with their abundance has been shown to provide relevant insight into the interaction between HRSC and the microenvironment in vivo [29]. Of note, our method of immunohistochemistry in fact is able to detect variability in PD1 expression as we have shown recently in patients suffering from a relapse after anti-PD1 treatment [12].

In summary, the number macrophages, a potential biomarker of outcome, remained stable between primary biopsy and relapse. The expression of therapeutic targets and potentially predictive biomarkers CD30, PD1, and PDL1 remain stable as assessed by immunohistochemistry between primary diagnosis and relapse. Thus, these biomarkers can be reliably assessed using the primary biopsy, e.g., if the biopsy confirming a relapse is not available or insufficient for ancillary studies. Of note, these findings 
are restricted to patients treated with conventional chemotherapy and biomarker might well be more variable when patients are treated with immune-checkpoint therapy [12]. Furthermore, the findings should be regarded as preliminary since the patient cohort analyzed in our study is limited.

Acknowledgements We would like to thank Charlotte Botz-von Drathen for her excellent technical assistance.

Author contribution AS, CWK, KR, and MS performed the research; AS, MS, and WK designed the research study; CT, FF, BF, PM, and RS contributed essential reagents or tools; CWK, RS, SR, and WK analyzed the data; and WK wrote the paper.

Funding information This work was supported in part by a grant of the German Cancer Aid (Deutsche Krebshilfe, No. 70112502).

\section{Compliance with ethical standards}

The study was conducted in accordance with the recommendations of the ethics board of the Medical Faculty, University of Kiel.

Open Access This article is distributed under the terms of the Creative Commons Attribution 4.0 International License (http:// creativecommons.org/licenses/by/4.0/), which permits unrestricted use, distribution, and reproduction in any medium, provided you give appropriate credit to the original author(s) and the source, provide a link to the Creative Commons license, and indicate if changes were made.

Publisher's note Springer Nature remains neutral with regard to jurisdictional claims in published maps and institutional affiliations.

\section{References}

1. Swerdlow SH, Campo E, Harris N, Jaffe E, Pileri S, Stein H, Thiele J, Vardiman JW (2008) WHO classification of tumors of the haematopoietic and lymphoid tissues. IARC, Lyon

2. Koh YW, Kang HJ, Yoon DH, Suh C, Kim JE, Kim CW, Huh J (2013) Changing trend of Epstein-Barr virus association in Hodgkin lymphoma in the Republic of Korea. Ann Hematol 92(12): 1653-1660

3. Kuppers R, Engert A, Hansmann ML (2012) Hodgkin lymphoma. J Clin Invest 122(10):3439-3447

4. Steidl C, Lee T, Shah SP, Farinha P, Han G, Nayar T, Delaney A, Jones SJ, Iqbal J, Weisenburger DD, Bast MA, Rosenwald A, Muller-Hermelink HK, Rimsza LM, Campo E, Delabie J, Braziel RM, Cook JR, Tubbs RR, Jaffe ES, Lenz G, Connors JM, Staudt LM, Chan WC, Gascoyne RD (2010) Tumor-associated macrophages and survival in classic Hodgkin's lymphoma. N Engl J Med 362(10):875-885

5. Devilard E, Bertucci F, Trempat P, Bouabdallah R, Loriod B, Giaconia A, Brousset P, Granjeaud S, Nguyen C, Birnbaum D, Birg F, Houlgatte R, Xerri L (2002) Gene expression profiling defines molecular subtypes of classical Hodgkin's disease. Oncogene 21(19):3095-3102
6. Sanchez-Aguilera A, Montalban C, de la Cueva P, Sanchez-Verde L, Morente MM, Garcia-Cosio M, Garcia-Larana J, Bellas C, Provencio M, Romagosa V, de Sevilla AF, Menarguez J, Sabin P, Mestre MJ, Mendez M, Fresno MF, Nicolas C, Piris MA, Garcia JF (2006) Tumor microenvironment and mitotic checkpoint are key factors in the outcome of classic Hodgkin lymphoma. Blood 108(2):662-668

7. Chetaille B, Bertucci F, Finetti P, Esterni B, Stamatoullas A, Picquenot JM, Copin MC, Morschhauser F, Casasnovas O, Petrella T, Molina T, Vekhoff A, Feugier P, Bouabdallah R, Birnbaum D, Olive D, Xerri L (2009) Molecular profiling of classical Hodgkin lymphoma tissues uncovers variations in the tumor microenvironment and correlations with EBV infection and outcome. Blood 113(12):2765-3775

8. Scott DW, Chan FC, Hong F, Rogic S, Tan KL, Meissner B, BenNeriah S, Boyle M, Kridel R, Telenius A, Woolcock BW, Farinha P, Fisher RI, Rimsza LM, Bartlett NL, Cheson BD, Shepherd LE, Advani RH, Connors JM, Kahl BS, Gordon LI, Horning SJ, Steidl C, Gascoyne RD (2012) Gene expression-based model using formalin-fixed paraffin-embedded biopsies predicts overall survival in advanced-stage classical Hodgkin lymphoma. J Clin Oncol 013 31(6):692-700. https://doi.org/10.1200/JCO.2012.43.4589

9. Ansell SM, Lesokhin AM, Borrello I, Halwani A, Scott EC, Gutierrez M, Schuster SJ, Millenson MM, Cattry D, Freeman GJ, Rodig SJ, Chapuy B, Ligon AH, Zhu L, Grosso JF, Kim SY, Timmerman JM, Shipp MA, Armand P (2015) PD-1 blockade with nivolumab in relapsed or refractory Hodgkin's lymphoma. N Engl J Med 372(4):311-319

10. Guo B, Cen H, Tan X, Ke Q (2016) Meta-analysis of the prognostic and clinical value of tumor-associated macrophages in adult classical Hodgkin lymphoma. BMC Med 14(1):159

11. Chan FC, Mottok A, Gerrie AS, Power M, Nijland M, Diepstra A, van den Berg A, Kamper P, D'Amore F, d'Amore AL, Hamilton-Dutoit S, Savage KJ, Shah SP, Connors JM, Gascoyne RD, Scott DW, Steidl C (2017) Prognostic model to predict post-autologous stem-cell transplantation outcomes in classical Hodgkin lymphoma. J Clin Oncol 35(32): 3722-3733. https://doi.org/10.1200/JCO.2017.72.7925

12. Sasse S, Reddemann K, Diepstra A, Oschlies I, Schnitter A, Borchmann S, Engert A, Borchmann P, Klapper W (2018) Programmed cell death protein-1 (PD-1)-expression in the microenvironment of classical Hodgkin lymphoma at relapse during antiPD-1-treatment. Haematologica 104(1):e21-e24. https://doi.org/10. 3324/haematol.2018.196279

13. Masque-Soler N, Szczepanowski M, Kohler CW, Spang R, Klapper W (2013) Molecular classification of mature aggressive B-cell lymphoma using digital multiplexed gene expression on formalin-fixed paraffin-embedded biopsy specimens. Blood 122(11):1985-1986

14. (2017) NanoStringQCPro: quality metrics and data processing methods for NanoString mRNA gene expression data. $\mathrm{R}$ package version 1.6.0. [computer program]

15. Malkov VA, Serikawa KA, Balantac N, Watters J, Geiss G, Mashadi-Hossein A, Fare T (2009) Multiplexed measurements of gene signatures in different analytes using the Nanostring nCounter Assay System. BMC Res Notes 2:80

16. NanoStringDiff: differential expression analysis of NanoString nCounter Data. R package version 1.6.0. [computer program]. 2015

17. Wang H, Horbinski C, Wu H, Liu Y, Sheng S, Liu J, Weiss H, Stromberg AJ, Wang C (2016) NanoStringDiff: a novel statistical method for differential expression analysis based on NanoString nCounter data. Nucleic Acids Res 44(20):e151. https://doi.org/10. 1093/nar/gkw677

18. Sanchez-Espiridion B, Sanchez-Aguilera A, Montalban C, Martin C, Martinez R, Gonzalez-Carrero J, Poderos C, Bellas C, Fresno MF, Morante C, Mestre MJ, Mendez M, Mazorra F, Conde E, Castano A, Sanchez-Godoy P, Tomas JF, Morente MM, Piris MA, Garcia JF (2009) A TaqMan low-density array to predict outcome in advanced Hodgkin's lymphoma using paraffin-embedded samples. Clin Cancer Res 15(4):1367-1375 
19. Steidl C, Connors JM, Gascoyne RD (2011) Molecular pathogenesis of Hodgkin's lymphoma: increasing evidence of the importance of the microenvironment. J Clin Oncol 29(14):1812-1826

20. Bennani-Baiti N, Thanarajasingam G, Ansell S (2016) Checkpoint inhibitors for the treatment of Hodgkin lymphoma. Expert Rev Clin Immunol 12(6):673-679

21. Vasef MA, Alsabeh R, Medeiros LJ, Weiss LM (1997) Immunophenotype of Reed-Sternberg and Hodgkin's cells in sequential biopsy specimens of Hodgkin's disease: a paraffin-section immunohistochemical study using the heat-induced epitope retrieval method. Am J Clin Pathol 108(1):54-59

22. Chu WS, Abbondanzo SL, Frizzera G (1992) Inconsistency of the immunophenotype of Reed-Sternberg cells in simultaneous and consecutive specimens from the same patients. A paraffin section evaluation in 56 patients. Am J Pathol 141(1):11-17

23. Ohsawa M, Aozasa K, Ikeda H (1993) Immunoreactivities of ReedSternberg cells and their variants in the sequential biopsy of Hodgkin's disease. Mod Pathol 6(4):457-462

24. Traverse-Glehen A, Pittaluga S, Gaulard P, Sorbara L, Alonso MA, Raffeld M, Jaffe ES (2005) Mediastinal gray zone lymphoma: the missing link between classic Hodgkin's lymphoma and mediastinal large B-cell lymphoma. Am J Surg Pathol 29(11):1411-1421
25. Hollander P, Kamper P, Smedby KE, Enblad G, Ludvigsen M, Mortensen J, Amini RM, Hamilton-Dutoit S, D'Amore F, Molin D, Glimelius I (2017) High proportions of PD-1(+) and PD-L1(+) leukocytes in classical Hodgkin lymphoma microenvironment are associated with inferior outcome. Blood Adv 1(18):1427-1439

26. Hollander P, Amini RM, Ginman B, Molin D, Enblad G, Glimelius I (2018) Expression of PD-1 and PD-L1 increase in consecutive biopsies in patients with classical Hodgkin lymphoma. PLoS One 13(9):e0204870

27. Taylor JG, Clear A, Calaminici M, Gribben JG (2019) Programmed cell death protein-1 (PD1) expression in the microenvironment of classical Hodgkin lymphoma is similar between favorable and adverse outcome and does not enrich over serial relapses with conventional chemotherapy. Haematologica 104(1):e42-e44

28. Okazaki T, Chikuma S, Iwai Y, Fagarasan S, Honjo T (2013) A rheostat for immune responses: the unique properties of PD-1 and their advantages for clinical application. Nat Immunol 14(12): $1212-1218$

29. Carey CD, Gusenleitner D, Lipschitz M, Roemer MGM, Stack EC, Gjini E, Hu X, Redd R, Freeman GJ, Neuberg D, Hodi FS, Liu XS, Shipp MA, Rodig SJ (2017) Topological analysis reveals a PD-L1 associated microenvironmental niche for Reed-Sternberg cells in Hodgkin lymphoma. Blood 130:2420-2430 